Notas

\title{
La apropiación de un universo diverso: La cuentística de Miguel Gomes
}

\author{
Grabbing a diverse universe: M iguel Gomes' narrative
}

Antonio García Lozada

Central Connecticut State U niversity. H artford, EE.UU.

E-mail: Garciaa@ccsu.edu

E

L AM PLIO bagaje cultural y la erudición de M iguel Gomes son dos de las

claves para entender la riqueza y complejidad de su mundo narrativo y ensayístico. Sus conocimientos no son mero almacenaje de saberes, sino que ha sabido emplearlos como herramienta para tratar de explicarse la realidad inmediata y la de sus lecturas. Sus escritos son expresión cabal de su mundo intelectual y afectivo. $\mathrm{H}$ a cultivado el ensayo y el cuento. D entro de su producción literaria se encuentran cuatro volúmenes de ensayos, cuatro de cuentos y un sinnúmero de artículos en publicaciones periódicas en Europa, Estados U nidos y América Latina. En sus cuentos - en los que centraré el presente trabajo-, desde la aparición de Visión memorable (1987), hasta Viviana y otrashistorias del cuerpo (2006), se escuchan múltiples voces, tonos y cadencias en las que se rescatan momentos que no se circunscriben a sugerir 0 a representar, sino que desvelan la diversidad de lo que se esconde detrás de ciertos objetos, ciertos comportamientos y ciertas actitudes. Esta es la apropiación que gesta M iguel Gomes de su diverso entorno, otorgándole un alto sentido estético.

No hay lugar a dudas que M iguel Gomes es uno de los mejores cuentistas venezolanos y latinoamericanos en el umbral del siglo XXI. En primer lugar, por la calidad de su prosa, cuidada, poética, precisa, que denotan unas grandes dotes de observación y un trabajo muy depurado. Junto a la calidad del estilo, la variedad de temas y por supuesto de personajes que oscilan entre la desazón que se produce en los ámbitos urbanos 0 en las cerradas sociedades académicas. Además de sus referencias insoslayables a Caracas, Portugal, o la isla de M adeira propiamente dicha, que sobresalen no tan sólo como una referencia del desplazamiento, "del lado de allá y del lado de acá"1, sino quetienen un sentido histó- 
rico y cultural y sobre todo mental aguijoneado por recuerdos de intensa vivencia.

Ahora bien, es probable que, valorada la obra con los típicos rótulos posmodernos de nuestra crítica actual, bien podría ser acusada de trivial o demasiada heterosexual, o carente de una dimensión moral profunda, por cuanto el narrador mueve a su regalado antojo los acontecimientos y los personajes transformándolos por momentos casi en caricaturas. Pero cierto es también que el manejo magistral de todos estos artificios, propios del arte de la ficción, son los que, en definitiva, consiguen configurar el universo genialmente lúdico de sus cuentos, Ilevándolos así al plano inequívoco de la ironía. Y es precisamente allí, al interior de esta denuncia descarnada y delirante tanto de la sociedad norteamericana como la de nuestra querida Latinoamérica, al igual que de los seres humanos mismos, donde cobra valor y sentido la ficción configurada por el juego mordaz y perfecto del autor. Así, Gomes pareciera estarnos diciendo a través de sus cuentos: nada tiene un sentido único, el ser humano -el ser inmerso y sacudido por las pasiones humanas, envidia, celos, voluptuosidad, ambiciones, soberbia, egocentrismo, etc.- es una buena porquería; un trozo de arcilla moldeable desde dentro según la conveniencia individual, como también desde fuera, por otros. N o obstante, bien se ve que M iguel Gomes, como verdadero artista, no pretende dejar mensaje al guno, salvo aquellos que se traslucen a través de su impecable juego de máscaras. Cuestión que molestaría en mucho a al gunos exegetas de los llamados "estudios culturales", especial mente a quienes no pueden distinguir entre ficción y realidad, como dimensiones esencialmente opuestas, pero paradójicamente confundibles medianteel uso dela maestría del narrador. Así, sus mensajes subliminales se limitan a poner de manifiesto que el artista no es más que un intermediario entre ficción y realidad, y que mientras mayor distancia exista entre una y otra, tanto mejor para la obra misma, como efectivamente ocurre en los cuentos de M iguel Gomes.

La cuentística de M iguel Gomes reflexiona sobrela vida ubicada en diversos lugares reales o imaginados: Caracas, Nueva York, O lot, M adeira, Bethesda, Washington D.C., H artford, N ew H aven, Long Island o M ystic, entre tantos otros. Pero estos espacios más que referencia cartográfica son el escenario donde confluyen el tiempo, el lenguaje y personajes que reiteran su condición de aves de paso por el mundo. Es decir que el espacio urbano, o rural, equiparable a la literatura testimonia las vivencias, tensiones, evocaciones, sueños y desencantos de sus habitantes. En el cuento "Travesía" que transcurre en la Caracas imaginaria, por ejemplo, el personaje central es uno de los tantos inmigrantes llegados a Venezuela que temen ser deportados de "la tierra prometida", lugar idealizado

\footnotetext{
${ }^{1}$ Parafraseo las coordenadas que traza Julio Cortázar en Rayuela.
} 
para el rebusque de la sobrevivencia humana. Sin embargo, se nos describe una Caracas con epítetos que reflejan hartazgo y que despunta por su sordidez. El personaje se enfrenta a los avatares de esa ciudad que ilustra un mundo abyecto en la que se le dificulta metafóricamente respirar, es estar como en una especie de "cárcel", donde no hay salida posible 2 . Y ante ese profundo sentir, surge la pregunta de rigor: "Q ué lejos queda el mar tras esa montaña" ${ }^{3}$. $Y$ lo que se transmite es el desarraigo, el extrañamiento, que produce aquella urbe "del lado de acá", contra el lugar indeterminado que se sitúa en "el lado de allá", que aún conserva la referencia ilusoria para el retorno.

El espacio urbano, 0 de suburbio, refleja en los cuentos de M iguel Gomes un estado de sopor. El bullicio de Caracas que se nos relata en "Travesía" no dista mucho del sentir del narrador-personaje en "N ew York, N ew York". En este cuento, el personaje se ha sumergido en la botella alcohólica como posible recurso para digerir la dureza y flotar ante la desolación que puede suscitar el mundo materialista e inhumano de la inmensa metrópoli neoyorkina. No obstante, el personaje nos presenta una clave, o guiño, que se pudiera apreciar como una propuesta literaria, esto es: la vida es literatura. La escritura según el personaje-narrador es una forma de sentirse vivo: En etepaísla vida que llevo es sobre todo, monótona; sólo estos soliloquiossin motivo disipan el agobio. (... ) Ya que no somos nada, al menos pongámoslo por escrito. - Venga ese trago ${ }^{4}$. A esta afirmación sobre la literatura como génesis de ella misma, podría aplicársele la ecuación de causa-efecto en el que su destino es la inevitabletarea de engendrar más literatura y para ello el narrador utiliza intrincadas cadenas de causas y efectos que reflejan las tensiones que se suscitan entre los seres humanos con la intención final de perpetuar la gran razón de la existencia (la literatura), y que constituye - para M iguel Gomes- la vida.

Ahora, pensar si los cuentos de M iguel Gomes se inspiran en la vida (sub) urbana o simplemente son la vida misma es ingenuo. Son ambos aspectos al tiempo, como la ficción y la realidad, que se traslapan, se superponen impidiendo distinguir claramente sobre qué círculo giramos. Centros urbanos como Caracas o N ueva York, entre otros, son una amal gama de culturas y de regiones; estas ciudades como la narrativa de M iguel Gomes son rizomáticas donde su estructura laberíntica nos tropieza con el pasado cuando pensamos en el futuro. Y una de las propuestas que discernimos en sus cuentos es la de una "narrativa rizoma". Se parte de reiterar ésta como un texto de confluencias temporales,

2 "Traveśáa", en La Cueva de Altamira. Colección O rinoco: Alfadil Ediciones, 1992, p. 17.

3 "Traveśa”, p. 17.

4 "N ew York, New York" en Viviana y otras historias del cuerpo. Caracas: Random H ouse M ondadori, 2006, pp. 27-28. 
donde el presente se concreta como el encuentro de elementos del pasado y del futuro deseado, donde la realidad escueta se toca con la ficción posible, es decir, donde la realidad se superpone a la fantasía construyendo un espacio único. La propuesta de la estructura y de la historia de algunos de sus cuentos sobre la construcción del imaginario citadino debe ser buscada, por un lado, como proposición intelectual, confluencia de tiempos y de espacios, y, por otro, como espacio real que está en la página escrita, en el lenguaje, en el gozo dela palabra, en la mezcla de los idiomas: español, inglés, catalán, latín, portugués, y está en la burla a la miseria de la vida, en la madurez que significa ser capaz de rérnos de nosotros mismos.

En un mundo como el hispanoamericano -y me refiero a los dos lados del Atlántico- la situación de desplazamiento voluntario u obligado, entendido este último como exilio o de corrientes migratorias, como lo ha señalado Antonio López 0 rtega ${ }^{5}$, adquiere una significación notable en los cuentos de M iguel G omes. D esplazamiento que en muchos casos genera la sensación de orfandad, de extrañamiento, pero sobre todo si ha sido obligatorio como se nos describe en "Un fantasma português, com certeza”: "A C aracasnoshabíamosvenido cuando tenía yo onceaños. La policía secreta deSalazar había obligado a papá a buscarse papeles de identidad falsos y a escapar del continente a las islas. Pasado el tiempo, con casa, trabajo e hijo, tuvo la idea genial deescribir y distribuir no séquépanfleto; pronto lo rastrearon y o Guilherme bragantino, como lo conocían los amigos, tuvo que poner pies en polvorosa, si así pudiera describirse una fuga marítima" ${ }^{6}$. Lo que viene después nos lo podemos imaginar: el desencanto del personaje al sentirse ajeno en ese nuevo sitio huraño y, por momentos, hostil. En el desplazamiento obligado la existencia asume un carácter provisional. Es decir, la condición de extranjero/exiliado, lejos de procurar una integración con el nuevo medio del cual letoca participar, ve acrecentarse progresivamentela sensación de precariedad y de aislamiento. Con sus ojos constantemente vuel tos hacia los contenidos de su memoria, el personaje central de este cuento se afirma en la convicción de que es totalmente ajeno a ese mundo y toda su existencia se concentra en la seguridad del regreso: "- Q uanto vol tamosa M adeira? Stou farto desta terra edesta gentaça"7. D e este modo, ni siquiera se concibe como alternativa la participación, aun de manera tangencial, de ese grupo humano con el cual le ha tocado en suerte convivir. A fuerza de ser más preciso, no puede hablarse de convivencia: el exiliado no "vive con", el exiliado vive "en sí" y para el universo del pasa-

\footnotetext{
${ }^{5}$ Antonio López O rtega, en Veintiuno. Caracas: diciembre 2004-enero 2005, p. 77.

6 "Un fantasma português, com certeza", en Fantasmas y destierros. M edellín: Fondo Editorial Universidad Eafit, 2003, p. 112.

7 "Un fantasma... ", p. 115.
} 
do, que se ofrece como la única realidad, en tanto que los seres que lo rodean asumen la condición de entidades casi fantasmales 0 , por lo menos, de puros accidentes que entorpecen el ansiado regreso: "M i madre y yo estábamos simétricamente solos, desconsolados, viudos"8. Esto confirma que aunque no existan los muros de la prisión como constituyente físico, los desplazados/extranjeros son consci entes de modo constante eirremediable desu condición de extrañamiento, de confinamiento y de inmensa soledad.

Esta situación de aislamiento, que pareciera poder revertirse hacia el pasado a través de un movimiento de regreso, es en verdad una condición de naturaleza irresoluble. Los personajes de "Un fantasma português, com certeza”, o M anuel Ramires D a C osta en "M ineta" al igual que Joaquim, profesor especializado en Garcilaso de la Vega en "Cuento de invierno", o Tom Vieira, doctorado en literatura comparada, en "Los abismos del mar", se encuentran suspendidos en una especie de atavismo y de atemporalidad míticos. Digo esto, en doble sentido: su presente -el del desplazamiento o constante peregrinación-, en la medida en que se alimenta de ese amargo sentimiento de frustración por no "ser parte de", por no estar integrado y ni siquiera contar con la fuerza espiritual para integrarse a esa comunidad de índole transitoria, es un presente en "estado puro", por decirlo de al guna manera, en tanto no se va haciendo y deshaciendo en términos de futuro y de pasado próximos. Su pasado - el de los recuerdos-, es absolutamente ilusorio, por el hecho de que el desplazado/extranjero quiere regresar a aquella realidad física y espiritual de la que ha sido desgajado con la vana pretensión de que todo está hecho de una vez y para siempre; vale decir que el regreso va a significar un reencuentro con las cosas, con los lugares, con las personas, en un mundo personal que se habrá mantenido invariable, tal como si ese transcurrir sin transcurso que caracteriza su presente en "estado puro" fuera la norma temporal que homologa también la esfera de los recuerdos más íntimos. M anuel Ramires da Costa, por ejemplo, reconfirma esta inmovilidad temporal como código sólo vigente para él mismo. El personajenarrador en "M ineta" no escatima en proporcionarnos esos detalles que reflejan las ataduras de Ramires D a Costa con su pasado marino - en Portugal- revivido ahora "al lado de acá" con su astillero en M ystic, Connecticut: Le pedí quevendiera el negocio y se viniera con nosotros, lo de apartarse del mar le parecía imposible, cas insultante. (... ) H asta recuerdo quellegó a en señarmelos bíceps, riéndose porquelos senhores doutores como yo se ponían blandos mucho antes de la primera cana?. Esto reconfirma también la imperiosa necesidad de Ramires $\mathrm{D}$ a C osta (como

\footnotetext{
8 "Un fantasma...", p. 115.

9 "M ineta", en Viviana y otras historias del cuerpo, p. 22.
} 
de otros personajes en los cuentos de M iguel Gomes), de cerrar un universo mental al discurso de los otros-las vivencias y los seres del pasado-, demodo tal que su propio discurso proyectado hacia los lugares que pretende conservar inalterables en su memoria no se vea perturbado.

A tenor de lo anterior, cabe detenerse en un punto que en alguna medida se hace conveniente precisar. M e refiero a la relación que existe entre la condición de la lejanía como efecto del desplazamiento y el lugar que ocupa el mito de la infancia. En este sentido, esimportante tener en cuenta queel tema de la infancia y el retorno a los orígenes es otro de los rasgos que aparece en algunos cuentos de $M$ iguel Gomes. El impulso espiritual que mueve a algunos de los personajes para reencontrarse con su infancia genera casi inevitablemente un sentimiento de ruptura, puesto que entra en conflicto el mundo de los recuerdos base de la formación de los mitos personales, del destino individual en última instancia- con el enfrentamiento directo con esa real idad que necesariamente se ha transmutado, aunqueya no exista posibilidad al guna o real de mirar el mundo con la ingenuidad del niño. Como dice el personaje-narrador en "M ineta": Las imágenes que conservo de la abuela -dudo que en la niñez me atreviera a llamarla vovó- son vagas. La única foto que mequeda de ella contribuye a perfilarla. $M$ is padres y yo nos fuimos de Portugal cuando yo tenía ocho años, la dejamos en el puerto, sacudiendo la mano para despedi $\mathrm{re}^{10}$, y esa imagen de la abuela, nexo con el pasado, no pasa a ser más que un ícono quesirve de referente en el intento de recuperar, intacta, la atmósfera de las primitivas experiencias infantiles. Aunque cabe reconocer que es en esa instancia primitiva en la que, a través de la construcción de la mitología personal, como he intentado puntualizar previamente, queda definido el sino particular de cada individuo.

El recurso al origen, a la inocencia de la infancia, corresponde al propósito de devolverleal pasado su prístina significación. En Gomes, ese propósito no lo condujo a las aventuras de un postmodernismo puramente estridente 0 al "manierismo", sino a un intento genuino de abarcar facetas del ser humano, gestos de insatisfacción, contenidos espirituales, pasando por esa vuelta a los lugares de la infancia, aun en el caso de que la experiencia cumplida demuestre que se trata de un regreso inútil. Así pues, esa búsqueda del contacto con el paisaje de la infancia no tiene como propósito primordial revivir las reminiscencias infantiles sino justamente intentar el rescate de ese pasado absoluto - absoluto en tanto se vincula con la visión mítica de la realidad-. D e tal manera resulta que la sacralización del pasado, que ha quedado definida como una nota particular del desplazamiento, es decir la reducción del presente a un "estado puro"

10 "M ineta", p. 15. 
como consecuencia de que la vida en el destierro queda desvirtuada por remisión a un pretérito de val or mítico, se extiende de manera irremediable al sentido último de la existencia como consecuencia de esa obstinada búsqueda por recuperar el paráso de la infancia.

Los cuentos de M iguel Gomes admiten indudablemente múltiples lecturas. Siendo esta una particularidad propia de las obras literarias de los grandes narradores. Alguien puede leerlos desde un punto de vista erótico, por cuanto la literatura erótica ofrece también esta dimensión proyectada - desde las primeras páginas en Viviana y otras historias del cuerpo- en los romances, los deseos y las magistrales descripciones que se entrecruzan en la cotidianidad de los personajes. También puede leerse desde una perspectiva académica propicia para conocer el intríngulis de la vida universitaria, en particular la pose de profesores 0 estudiantes de literatura que enfrascados en un ámbito de banalidades seufanan de ser los exegetas de la literatura universal y, por ende, de la latinoamericana. Sin embargo, avanzando un poco más allá de las líneas generales alzadas por los trazos del narrador, los tres libros de cuentos: Fantasmas y destierros, Un fantasma portuguésy Viviana y otras historias del cuerpo (publicados en un período de tres años) cobran una perspectiva lúdica de dimensiones sin iguales, a mi juicio, dentro del marco de la cuentística latinoamericana. M iguel Gomes, con un juego de máscaras y mundos delirantes cuajados de fantasmagorías, aborda magistralmente un universo cerrado y complejo: el ámbito universitario estadounidense.

En mi opinión, el fino humor de M iguel Gomes alcanza su más perfecta madurez como cuentista en estos últimos tres libros que parecen estar encerrados dentro "del mismo impul so y proyecto narrativo"11. En estostextos seintenta además abordar una amplia gama de situaciones conflictivas del ser humano, tanto políticas como sociales, intelectuales, morales, existenciales, individuales, sexuales, etc., desde el interior siempre delirante de los acontecimientos donde se mueve esta comparsa bufonesca de personajes heterogéneos, provocando una risa constante al lector, y sin salirse, en momento alguno, de su condición de personajes exclusivamente ficcionales, para no traicionar al autor, ni a los cuentos mismos, como objeto puramente artístico. D esfilan por los escenarios estudiantes, profesores, intelectuales, críticos literarios en encuentros de voces y cuerpos que con un espíritu perverso permean erotismo y el efecto de estos encuentros se hilvana a un lenguaje cargado de ironía, humor y sensualidad. En este sentido, la literatura y la vida se fusionan y de ahí que vale la pena aceptar la seducción que nos propone M iguel Gomes.

Por otra parte, si bien el humor se utiliza en los pasajes que describen el

${ }^{11}$ Carlos Pacheco, en Imagen (C aracas), febrero-abril, 2005, año 38, № 2. 
placer de los cuerpos en los momentos de erotismo, éstos se entrecruzan con el placer de la lectura, la alusión al arte pictórico, o la referencia concreta a la escritura. Aquí hallamos una amplia empatía artística (aclaro que evito el trillado y vacío término de intertextualidad), que se extiende como un abanico hacia autores latinoamericanos como Borges, $\mathrm{N}$ eruda, entre otros; aludiendo también a los mundos poéticos de $G$ arcilaso, Pessoa, Pavese, Kafka a través de un recuento nostálgico y poético de parte de sus variados personajes. Y todavía va másallá, atraviesa mares y fronteras -si es que éstas existen entre las obras literarias- dando una mirada a otros maestros de la literatura universal: H omero, D ante, $\mathrm{H}$ emingway, $\mathrm{N}$ abokov, Zolá, etc. Los cuentos, en este sentido, abren un amplio escenario propicio para la discusión constructiva, tan necesaria para el arte; gratuitamente regalada por el autor desde su vasto imperio del conocimiento de la literatura universal. Solamente desde esta perspectiva, su obra cuentística se constituye en la literatura latinoamericana como una de las más reveladoras de tales asuntos y que para estudiantes de literatura, o lectores comunes, debe resultar de interés esencial.

En suma, cuando los personajes se nos presentan, la acción - que se desarroIla dentro de escenariosmínimos, pero escogidos con mano maestra- comienza a acelerar su curso hasta llegar a momentos de efervescencia máxima con la yuxtaposición de escenas de envergadura intelectual, nostálgica, existencial y erótica, donde los personajes son exprimidos por la fantasía del autor que no escatima artificios para proyectarlos en dimensiones tanto humanas como caricaturescas, abriendo así infinidad de puertas para el diálogo fuera del universo de los cuentos mismos, asunto que es tan poco común en las obras de nuestra narrativa latinoamericana, donde impera notablemente la monofonía y escasea la comparsa polifónica de voces. El manifiesto romance entreTom V iejra y K atie pareciera por momentos ser el eje central del cuento "Los abismos del mar" y desde donde surge la mayor dosis de suspenso. Sin embargo, debido a la ambigüedad de esta gringa colosal, esposa desu íntimo amigo J onathan 0 'Toole, quien entusiasma y seduce aTom a la intensa pasión erótica, contribuye a queel cuento cobre matices propicios para clímax delirantes y cargados deambival encia. Esto se evidencia, por ejemplo, al final del cuento cuando Tom: "Antes de levantarse, se recorrió todo el cuerpo con las manos. Estaba intacto, excepto por el chichón en la cabeza, y la ropa, quetenía desgarrones. 0 tro detallemás le llamó la atención: la erección aún no cedía. Ya vería qué hacer al respecto, cuando llegase a M ystic"12. Así, la realidad está permanentemente cuestionada por la realidad virtual, como también la identidad de los personajes. Estejuego mag-

12 “Los abismos del mar", en Un fantasma portugués. Caracas: Otero Ediciones, 2004, p. 59. 
nífico de ambivalencias hace que el cuento adquiera la dosis de ficción suficiente para recrear la simpleza en sí de la anécdota.

M iguel Gomeses, en mi opinión, un maestro genial para esta clasede finales inesperados, y tanto en "Los abismos del mar" como en los otros cuentos reunidos en Fantasmas y destierros, Un fantasma portugués y Viviana y otras historias del cuerpo lo consigue plenamente. 
